Materiales de Construcción

Vol. 64, Issue 313, January-March 2014, e005

ISSN-L: 0465-2746

http://dx.doi.org/10.3989/mc.2014.00813

\title{
Fracture energy evolution of two concretes resistant to the action of freeze-thaw cycles
}

\author{
A. Enfedaque $₫$, H.L. Romero ${ }^{a}$, J.C. Gálvez \\ a. Universidad Politécnica de Madrid. (Madrid, España) \\ $\bowtie$ alejandro.enfedaque@upm.es
}

Received 25 January 2013

Accepted 29 October 2013

Available on line 12 March 2014

\begin{abstract}
The current standards that regulate use of structural concrete have highlighted the durability of concrete. However, how the fracture energy of concrete evolves under the action of freeze-thaw cycles is not well known. The fracture energy of two types of concrete, one with an air-entraining additive and the other with silica fume addition, is studied after four, 14 and 28 freeze-thaw cycles. The results obtained show that the concrete with an air-entraining additive was undamaged and that fracture energy grew slightly. In addition to this, they also showed that the concrete with silica fume addition suffered severe surface scaling and its fracture energy changed due to the greater fracture areas generated.
\end{abstract}

KEYWORDS: Concrete; Freezing-thawing, Air-entraining additive; Silica fume

Citation / Citar como: Enfedaque, A.; Romero, H.L.; Gálvez, J.C. (2014). Fracture energy evolution of two concretes resistant to the action of freeze-thaw cycles. Mater. Construcc. 64 [313], e005 http://dx.doi.org/10.3989/mc.2014.00813

RESUMEN: Evolución de la energía de fractura de dos hormigones resistentes a la acción de ciclos hielo-deshielo. La actual normativa que rige el empleo de hormigón estructural ha puesto enfásis en la durabilidad del hormigón. Sin embargo, no se conoce cómo evoluciona la energía de fractura del hormigón sometido a ciclos hielodeshielo, lo cual es de vital importancia para asegurar la durabilidad y el correcto comportamiento mecánico de las estructuras de hormigón en entornos con heladas durante su vida útil. Se ha estudiado la evolución de la energía de fractura de un hormigón con aireante y de un hormigón con humo de sílice después de 4, 14 y 28 ciclos hielo-deshielo realizando ensayos de fractura. Los resultados muestran cómo el hormigón con aireante no sufre daño por los ciclos hielo-deshielo y cómo la energía de fractura del mismo aumenta ligeramente. El hormigón con humo de sílice se daña por los ciclos hielo-deshielo y reduce su energía de fractura al aumentar el area fracturada.

PALABRAS CLAVE: Hormigón; Hielo-deshielo, Aditivo inclusor de aire; Humo de sílice

Copyright: (C) 2014 CSIC. This is an open-access article distributed under the terms of the Creative Commons Attribution-Non Commercial (by-nc) Spain 3.0 License.

\section{INTRODUCTION}

The Spanish Standard of Structural Concrete EHE-08 (1) prescribes a service life of 50 to 100 years for the greater part of civil engineering concrete structures. In countries with a continental climate, such as Spain, a frequent cause of concrete deterioration is attack by freeze-thaw cycles. Given that the number of publications that examine the various aspects of concrete under freeze-thaw cycles is extremely large, it is not the objective of the authors to provide a summary in such a short paper. Many of them deal with the mechanisms and factors that influence such a phenomenon. 
Jacobsen (2) studied the effect of the cooling rate on the damage of concrete and concluded that surface damage was greater when the cooling rate was lower, while internal damage was greater at higher speeds of cooling. Moreover, the study pointed out that there was a relationship between external and internal damage to the concrete, with the latter being more important at greater degrees of external damage. Other works have studied the influence of the concentration of chloride ion in an aqueous solution which is in contact with the concrete $(3,4)$. These works have concluded that the concentration of $\mathrm{Cl}^{-}$that causes most damage in the concrete surface is $3 \%$.

Apart from the contributions of these studies, it is widely known that the way to achieve a good durability in the concrete when it is subjected to freezethaw cycles is by incorporating an air-entraining additive $(5,6)$. However, when using bonded prestressed tendons, use is prohibited both in the current Spanish Standard of Structural Concrete EHE-08 (1) and in other codes. In such a case, an alternative is the dosage of a concrete with a more closed pore structure, which may be achieved through the addition of silica fume to concrete $(7,8)$. Based on this idea, concretes with high resistance to freezethaw cycles were obtained, both under laboratory conditions and cast in situ (9). However, the more in-depth study on this issue offered by Al-Assadi and Romero has shown that this alternative is not as effective as the incorporation of an air-entraining additive (10-12).

The influence of freeze-thaw cycles on the mechanical behaviour of concrete has also been examined in the literature. Several studies have shown the influence that such cycles have on concrete without an air-entraining additive or silica fume subjected to both biaxial and tri-axial loading, $(13,14)$ with failure criteria being proposed. These studies have also been performed for concrete with an air-entraining additive, with the conclusion being that a large number of freeze-thaw cycles applied to this concrete diminishes their mechanical properties when it is subjected to uniaxial and tri-axial compression loading $(15,16)$.

None of the above works, however, has paid attention to the evolution of the fracture energy of concrete subjected to the action of freeze-thaw cycles. This material property is highly significant, since the cracking and its evolution over time have a direct influence on the durability and the mechanical behaviour of concrete.

Currently, assessment of durability of concrete in freeze-thaw cycles is carried out by using two types of test: study of internal damage by cracking and surface scaling resistance. Neither method can completely simulate the actual conditions of attack in the concrete subjected to freeze-thaw cycles, although it should be noted that the choice is made in order to reproduce the environment where the structure is located. There are various standards and recommendations with UNE-CEN/TS 12390-9 (17), which measures scaling resistance, being applied in Spain.

With the aim of adding to the studies already published on the influence of freeze-thaw cycles on the mechanical properties of concrete, the evolution of the fracture energy of two concretes is studied, one made with an air-entraining additive and the other with partial replacement of cement by silica fume. The tests were performed before and after the concrete was subjected to freeze-thaw cycles, following the standard (17). Techniques for measuring the evolution of the scaling, complementary to those included in the standard, are also used in this work.

\section{MANUFACTURE AND PROPERTIES OF THE CONCRETES STUDIED}

Two concretes were tested. The mixes were cast by using the same cement: CEM I $42.5 \mathrm{R}$. The aggregate consisted of siliceous sand (grade $0 / 5$ ) and gravel (grade 5/20). Whereas the fineness modulus was 2.87 for sand, it was 7.31 for gravel. SIKA Viscocrete $20 \mathrm{HE}$ superplasticizer was added to both concretes and SIKA Aer additive to the concrete with an air-entraining additive. Table 1 shows the dosage of the concretes, with AEAC being the concrete with air-entraining additive and SFC that with silica fume.

Partial replacement of cement with silica fume was $10 \%$ of the weight of the cement. An effectiveness factor of two was adopted for silica fume. The total amount of binder material was $400 \mathrm{~kg}$ (per cubic meter). Table 1 shows the water/binder ratio.

TABLE 1. Concrete mix proportions

\begin{tabular}{lcc}
\hline Material & AEAC & SFC \\
\hline Cement $\left(\mathrm{kg} / \mathrm{m}^{3}\right)$ & 425 & 320 \\
Silica Fume $\left(\mathrm{kg} / \mathrm{m}^{3}\right)$ & - & 40 \\
Water $\left(\mathrm{kg} / \mathrm{m}^{3}\right)$ & 170 & 180 \\
Fine aggregate $\left(\mathrm{kg} / \mathrm{m}^{3}\right)$ & 630 & 565 \\
Coarse aggregate $\left(\mathrm{kg} / \mathrm{m}^{3}\right)$ & 1100 & 1266 \\
Superplasticizer $\left(\mathrm{kg} / \mathrm{m}^{3}\right)$ & 1.5 & 1.8 \\
Air entraining agent $\left(\mathrm{kg} / \mathrm{m}^{3}\right)$ & 0.34 & - \\
w/(c+Kf) & 0.4 & 0.45 \\
\hline
\end{tabular}

TABLE 2. Concrete fresh properties

\begin{tabular}{lcc}
\hline Concrete properties & AEAC & SFC \\
\hline Slump test $(\mathrm{cm})$ & 14 & 12 \\
Air content $(\%)$ & 5.7 & 1.4 \\
\hline
\end{tabular}


TABLE 3. Mechanical properties of concrete

\begin{tabular}{lcr}
\hline Concrete properties & AEAC & SFC \\
\hline Compressive strength 7 days $(\mathrm{MPa})$ & 27.2 & 28.9 \\
Compressive strength 28 days $(\mathrm{MPa})$ & 34.7 & 33.1 \\
Modulus of elasticity $(\mathrm{GPa})$ & 22.7 & 24.9 \\
Indirect tensile strength $(\mathrm{MPa})$ & 3.19 & 3.2 \\
\hline
\end{tabular}

The concrete was mixed by using a vertical-axis planetary mixer with a capacity of 1001 . The specimens were cast at room temperature.

The consistency of the concrete was measured with a slump test. Air entrainment was measured according to the ASTM C 231 (18) standard. Table 2 shows the measured values.

For each concrete the following specimens were manufactured: 16 prisms with dimensions of $430 \times 100 \times 100 \mathrm{~mm}^{3}$ and six cylinders of $300 \mathrm{~mm}$ in height and diameter of $150 \mathrm{~mm}$ which were used for the characterisation of the material.

For the first 24 hours the specimens were kept in moulds at laboratory temperature and covered with wet sacking. All the specimens were demoulded after 24 hours. They were subsequently stored in a climatic chamber at $20{ }^{\circ} \mathrm{C}$ and $95 \%$ relative humidity for 28 days. Then one of the prismatic specimens, for each concrete, was cut and four prims with dimensions of $70 \times 100 \times 100 \mathrm{~mm}^{3}$ obtained. All were submerged in a water bath at $20 \pm 2{ }^{\circ} \mathrm{C}$ for seven days, and then stored in a climatic chamber at $20^{\circ} \mathrm{C}$ and $95 \%$ relative humidity for 21 days.

The cylindrical specimens were subjected to mechanical characterisation tests. Compression tests were carried out at seven and 28 days and indirect tensile strength (Brazilian test) measured at 28 days. The results obtained are shown in Table 3 where the average value of three specimens is presented.

\section{EXPERIMENTAL PROGRAMME}

The experimental programme was carried out in two phases: the specimens were first subjected to freeze-thaw cycles and then notched and fractured to measure the fracture energy of each type of concrete after freeze-thaw cycles.

\subsection{Freezing-thawing tests}

All specimens, both those cut and the rest of each type of concrete, were subjected to freeze-thaw cycles according to standard UNE-CEN/TS 12390-9 (17). Cycles were initiated when the specimens were 28 days old, with each having a duration of 12 hours and a range of variation of temperature of $20{ }^{\circ} \mathrm{C}$ to $-20{ }^{\circ} \mathrm{C}$, as shown in figure 1 . During the cycles, the specimens were partially submerged $(10 \mathrm{~mm})$ in a solution of deionised water with $3 \%$ of $\mathrm{NaCl}$.

The surface scaling was measured after four, 14 and 28 cycles. Measurement was performed by withdrawing the attached particles from the surface of the specimens, using an ultrasonic bath. Then the solution that contained the removed material was filtered and dried for 24 hours at $100{ }^{\circ} \mathrm{C}$. The material was weighed after reaching room temperature. The result is expressed in accordance with [1]:

$$
m_{n}=\frac{\sum \mu_{n}}{A}
$$

Where $m_{n}$ is the accumulated mass of pulled away material per unit area after $n$ cycles expressed in $\mathrm{kg} / \mathrm{m}^{2}, \Sigma \mu_{n}$ is the accumulated mass of dry material separated after $n$ cycles in grams and $A$ is the total testing area in $\mathrm{mm}^{2}$.

In order to complete the measurements prescribed by the standard (17), in each specimen for each cycle of study (four, 14 and 28 cycles) a measurement of the speed of an ultrasonic pulse through it was performed. This measurement was made with

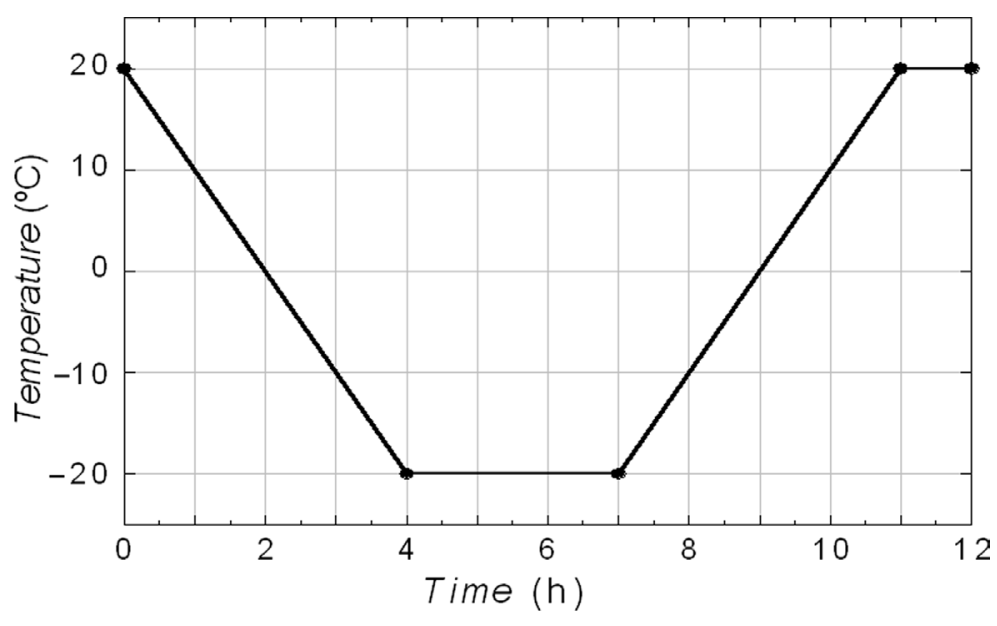

FIGURE 1. Freeze-thaw cycle. 
a portable device that has a transmitter and receiver of the ultrasonic pulse and which were placed on opposite sides of the specimen. An ultrasonic pulse velocity measurement was carried out in three directions normal to the specimen: length (direction $l-l$ '), width (direction $t-t^{\prime}$ ) and height (direction $\left.h-h^{\prime}\right)$. By comparing the measurement recorded in cycle $n$ with the measurement taken before submitting the concrete to the freeze-thaw cycle, the decrease of the modulus of elasticity was obtained.

This variation was due to the internal damage and can be expressed as follows [2]:

$$
R D M E(\%)=\frac{v_{n}^{2}}{v_{0}^{2}} \times 100
$$

Where $v_{n}$ is the transversal velocity of ultrasonic pulse after ${ }^{n} n$ cycles in $(\mathrm{m} / \mathrm{s}), v$ is the transversal initial velocity of ultrasonic pulse in the cycle zero in $(\mathrm{m} / \mathrm{s})$.

Bishnoi \& Uomoto (19), among others, pointed out that concrete shows dimensional changes during the freeze-thaw cycle as a result of material damage, something that this work has addressed. The surface deformation was recorded by using strain gauges; a system that had already provided satisfactory results in previous studies $(20,21)$. In addition, as the system allows a continuous measurement of dimensional changes it provides details of the behaviour of the material through all cycles. These strain gages were glued to the prismatic specimens of $430 \times 100 \times 100 \mathrm{~mm}^{3}$ in the centre of a side face of the test specimen at $30 \mathrm{~mm}$ from the surface in contact with the medium of freezing. Figure 2 shows a sketch of the placement of the bands in the specimens.

\subsection{Fracture tests}

Fracture tests were performed on the prismatic specimens with dimensions $430 \times 100 \times 100$ $\mathrm{mm}^{3}$, following the recommendations of RILEM TC-187-SOC (22) and RILEM 50-FMC (23). The distance between rolling supports was $4 D$, with $D$ being the depth of the specimen. The tests were performed for measuring the evolution of specific fracture energy caused by the freeze-thaw cycles on the specimens and carried out with notched specimens. The depth of the notch was $D / 3$, which was

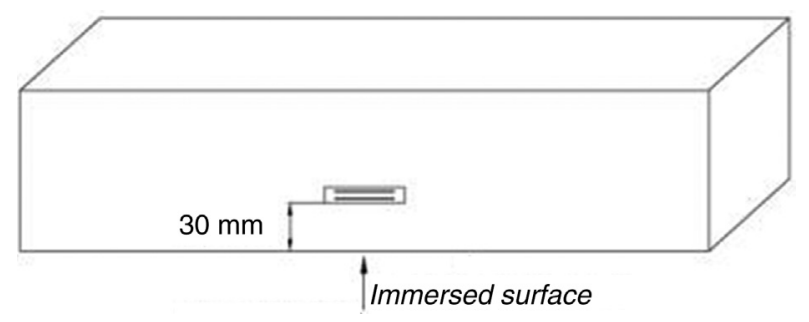

FIgURE 2. Strain gauge location on the prismatic sample.

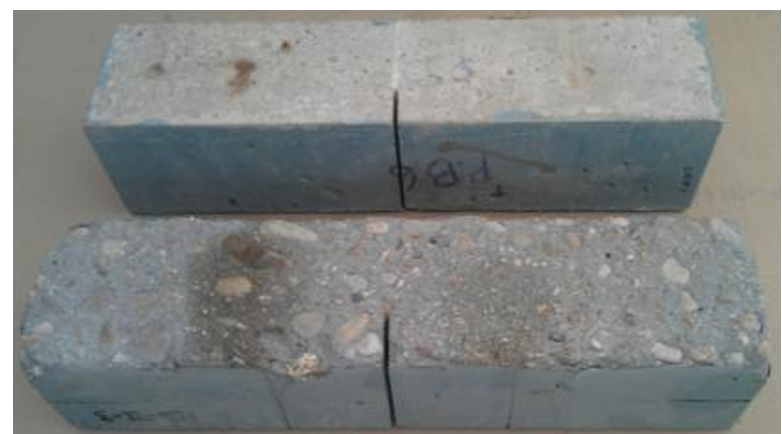

Figure 3. Samples subjected to 28 freeze-thaw cycles already notched. SFC front, AEAC rear.

placed at the middle of the specimen on the plane where the load was applied. The specimens were placed in such a way that the surface subjected to freeze-thaw testing was one of the side faces during the test (see figure 3 ).

Thus, while there is a part of the damaged area that has no influence on the fracture energy (as it has been notched), two-thirds of the area will be subjected to the fracture process.

The tests were performed under crack mouth opening displacement (CMOD) control. Two steel sheets were placed at each side of the notch for placing the CMOD extensometer. The cover of epoxy resin was removed to fix each steel support. The layer of epoxy resin that covered the lateral surfaces of the specimen was applied to the freeze-thaw testing (17). Table 4 shows the CMOD velocity during the test.

Two linear variable differential transformers (LVDTs) extensometers were placed at the sides of the specimen for recording deflection. Load and position were also recorded during testing. Figure 5 shows a specimen under testing.

As figure 5 shows, there was not any weight compensation during testing, by which self-weight was taken into account in the fracture energy evaluation.

For SFC, the tests were performed for sound specimens and after four, 14 and 28 freeze-thaw cycles. Since previous works (24) have shown a good resistance of AEAC against freeze-thaw cycles, for this concrete the specific fracture energy was measured for sound specimens and after 14 and 28 freeze-thaw cycles, without any evaluation at four cycles.

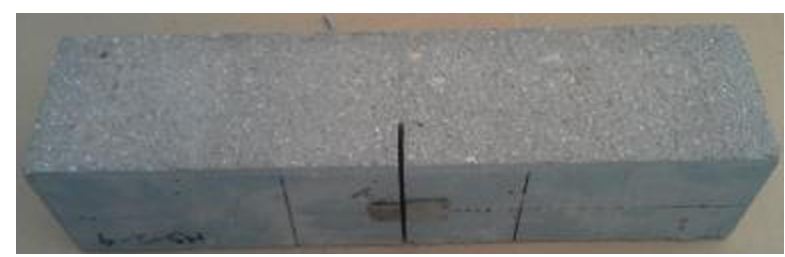

Figure 4. Notched sample with the CMOD knife-edges already placed. 
TABLE 4. CMOD opening velocity

\begin{tabular}{lc}
\hline CMOD $(\boldsymbol{\mu m})$ & Opening velocity $(\mu \mathrm{m} / \mathbf{s})$ \\
\hline $0-150$ & 0.20 \\
$150-250$ & 0.40 \\
$250-400$ & 1.00 \\
$400-1500$ & 2.00
\end{tabular}

\section{RESULTS}

\subsection{Freeze-thaw tests}

Twelve prismatic samples and the four samples with dimensions $70 \times 100 \times 100 \mathrm{~mm}^{3}$ cut from one of the prismatic samples of the two types of concrete were subjected to the stages of the freeze-thaw cycles. Three prismatic samples of each of the concrete formulations were stored in a curing chamber to be used as a reference in the fracture tests. After four freeze-thaw cycles, four samples of each formulation were taken from the climatic chamber and stored in the curing chamber until testing. This process was repeated after 14 and 28 cycles.

In figure 6 the appearance of the samples after 28 freeze-thaw cycles may be seen. The concrete with silica fume addition underwent noticeable surface damage (in some samples the aggregates can be clearly seen). In addition, in a few samples some gravel was lost as a consequence of such damage. In contrast, the samples manufactured with an airentraining additive showed only a minor surface damage. Only small cavities may be seen on the surface of the samples and no aggregate was expelled from the sample.

The damage in the concrete was determined by measuring the surface mass loss, monitoring the strain of the samples and obtaining the dynamic elastic modulus.

In figure 7 the surface mass loss may be seen. The surface damage in concrete SFC was noticeably higher than in AEAC concrete. The amount of mass



Figure 5. SFC simple during a fracture energy test.
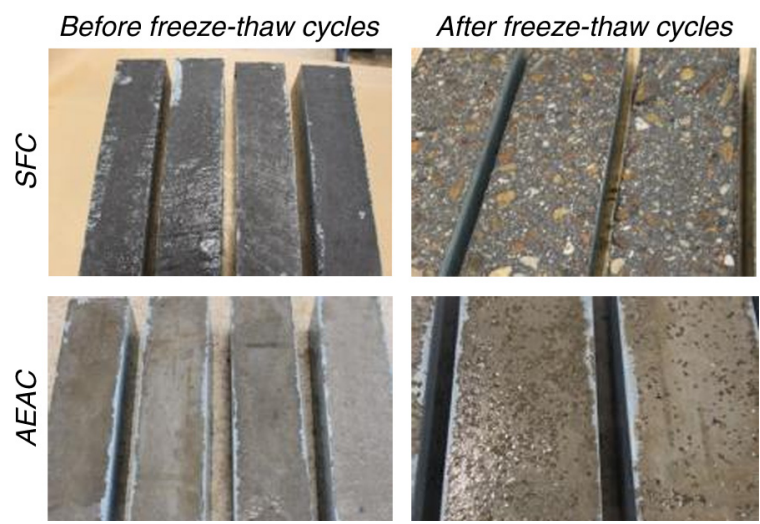

FIGURE 6. Simple appearance before and after the freeze-thaw cycles.

loss in SFC concrete exceeded the limit established in the test recommendation used. On the contrary, AEAC concrete only showed a limited damage somewhat far from the limit previously mentioned.

The strain evolution in concrete during one of the freeze-thaw cycles may be seen in figure 8. In contrast to what might be expected, during the cooling part of the cycle the concrete shrinks due to the suction that takes place in the pores caused by the difference in the thermal expansion coefficient of the freezing solution and concrete. This causes a reduction in the dimensions of the samples, as previously shown and explained by other authors $(19,25)$. The expansion of the concrete occurs, consequently, in the heating part of the cycle where the effect of the suction disappears. This behaviour can be explained by previously published models (26).

The expansion-shrinkage process can be observed upon examining figures 1 and 8 together. Figure 1 shows that in the first four hours of the cycle the

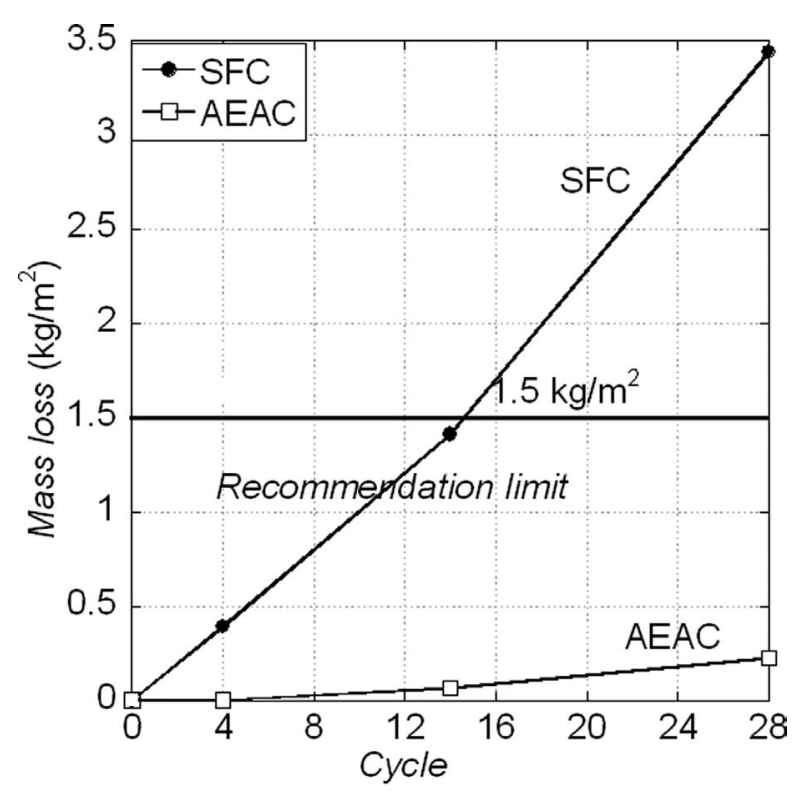

FIgURE 7. Surface mass loss in SFC and AEAC. 


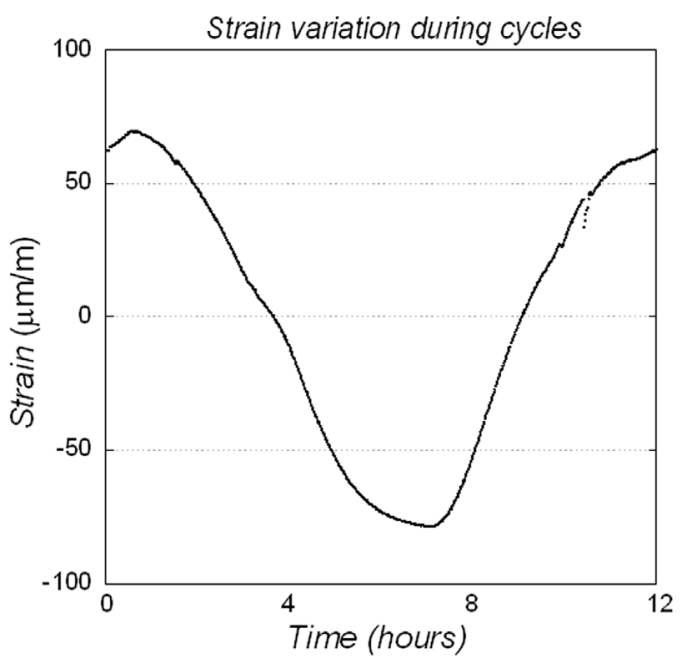

Figure 8. Strain variation during a freeze-thaw cycle.

temperature reaches $-20{ }^{\circ} \mathrm{C}$ and is constant for the following three hours. The effect of this temperature is a contraction and stabilisation of the dimensions of the sample. Then, the temperature is constantly increased up to $20^{\circ} \mathrm{C}$ and maintained constant for an hour. Simultaneously, the samples begin to dilate.

The continuous measurement of the strain of the samples enables study of the changes in the geometry of the samples from the first cycle to the last of the 28 cycles that the respective recommendation establishes.

The strain evolution of the samples of the two types of concrete can be seen in figure 9, which shows how the dimensions of the samples of AEAC

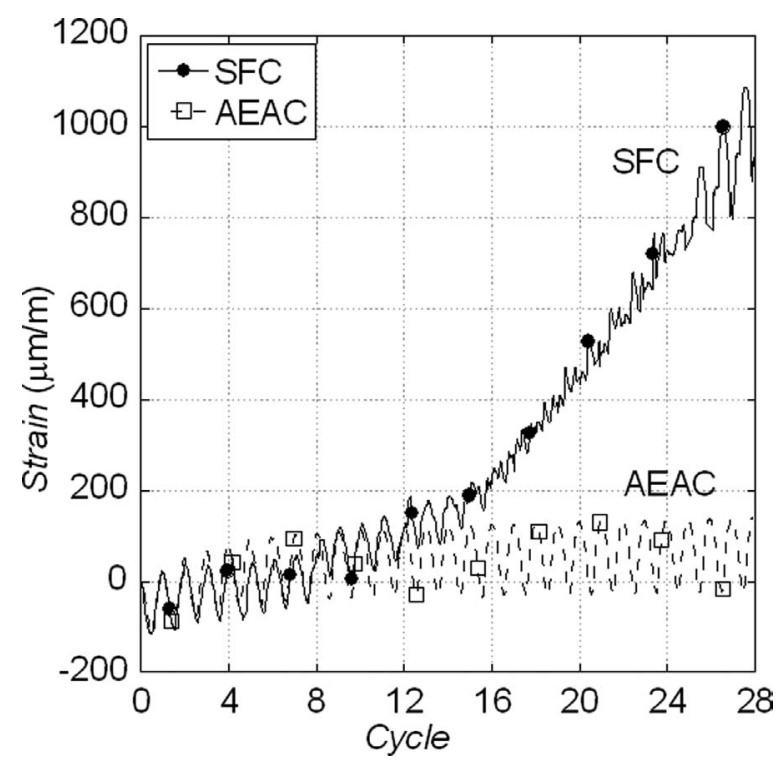

FIGURE 9. Surface strain in one prismatic sample of SFC and AEAC.

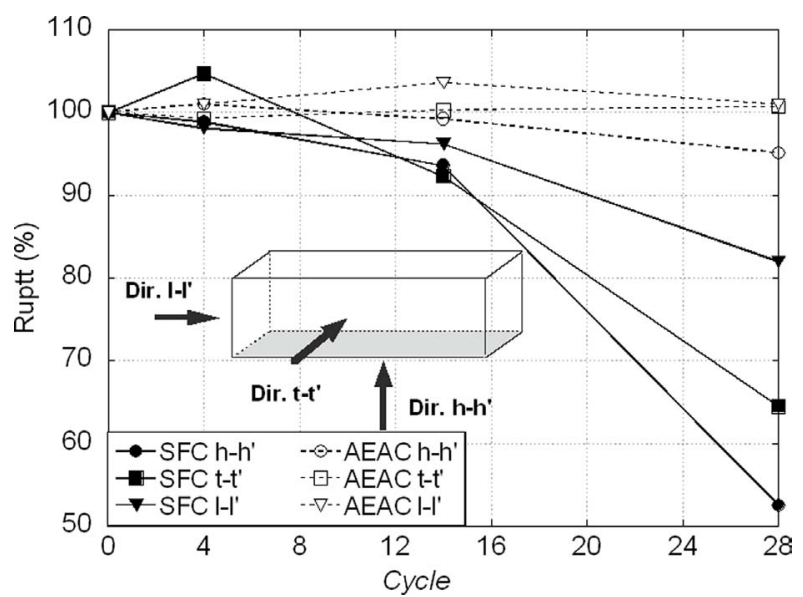

Figure 10. Dynamic elastic modulus variation in SFC and AEAC samples.

concrete grew slightly until cycle 9 and were constant afterwards. Conversely, the strain of the SFC samples underwent minor changes until cycle 12, the point from which the dimensions increased rapidly and reached values of over 1000 microns per meter.

In order to complete the characterisation of the damage caused during the freeze-thaw cycles, a study of the variation of the dynamic elastic modulus of the prismatic samples was performed. Measurements were taken of the length (1-1'), width $\left(\mathrm{t}-\mathrm{t}^{\prime}\right)$ and depth (h-h') of the samples, carried out at the end of four, 14 and 28 cycles. The results obtained may be seen in figure 10 .

The results gathered in the AEAC concrete showed small variations of the ultrasonic pulse velocity during the freeze-thaw cycles. The greatest differences were obtained in the height of the samples, with this being close to a $5 \%$ variation. In these measurements, one of the gauges was in contact with the surface of the sample immersed in the freezing solution. A constant value was obtained in the measurements taken in the width of the samples, whereas in the length of the samples there was a fluctuation between cycles 14 and 28 .

However, the results obtained in SFC concrete showed notable changes when compared with the undamaged state of the samples. As happened in AEAC samples, the greatest differences were obtained in the height direction (h-h'). The variation in SFC samples was almost $50 \%$ of the undamaged values. This tendency was also observed in the rest of the directions, with a $35 \%$ variation in the width direction (t-t') and almost a $20 \%$ variation in the length direction (1-1').

\subsection{Fracture tests}

Fracture tests were performed in the prismatic samples with dimensions of $430 \times 100 \times 100 \mathrm{~mm}^{3}$. The conditions of the tests were identical for both 


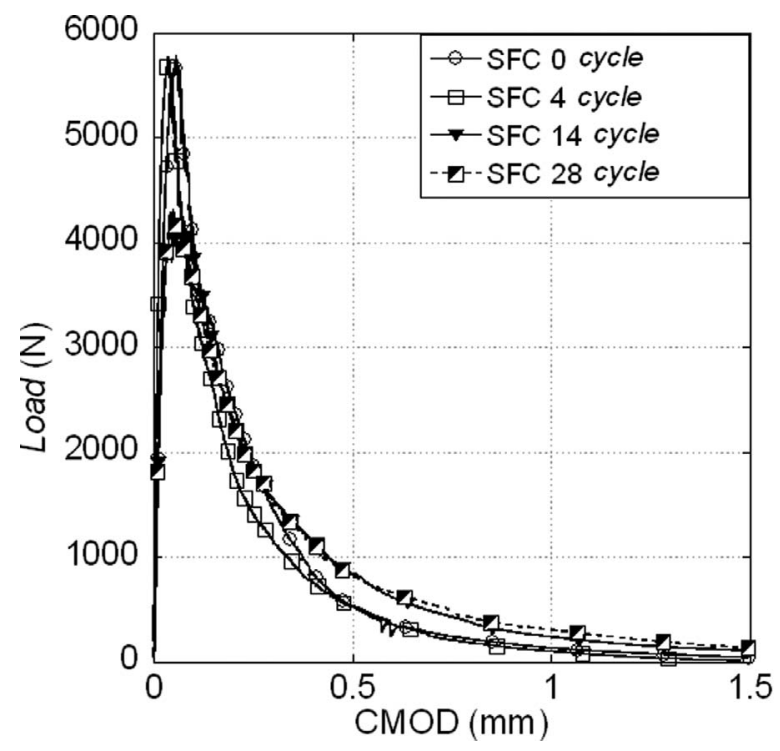

FIGURE 11. Fracture tests in SFC samples before and after freeze-thaw cycles.

the undamaged samples and the samples subjected to the freeze-thaw cycles. The former were considered as the reference value.

During the tests no torsion stresses and strains were noticed, even though one of the sides of the samples subjected to the freeze-thaw cycles was damaged which meant that the section was asymmetrical. The mass loss in the damaged side was not enough to cause a noticeable change in the torsional inertia of the samples, which was checked by comparing the data registered by the LVDT devices placed at both sides of the samples.

The results of the fracture tests of the SFC undamaged samples and of the SFC samples after four, 14 and 28 freeze-thaw cycles can be seen in figure 11. It shows that the samples after 14 and 28 cycles had a maximum load lower than the undamaged samples and the sample after four cycles. In addition, it was also clear that the unloading branch of the tests of the samples after 14 and 28 cycles was more gradual than the rest of the samples. This can be noticed when comparing the load of the samples at the same CMOD value.

The results of three of the tests performed on samples manufactured with an air- entraining additive can be seen in figure 12 . The variations were

TABLE 5. Concrete fracture energy

\begin{tabular}{lcc}
\hline & \multicolumn{2}{c}{ Concrete fracture energy (N/m) } \\
\cline { 2 - 3 } & SFC & AEAC \\
\hline 0 cycles & 159.44 & 169.92 \\
4 cycles & 145.35 & - \\
14 cycles & 152.65 & 184.84 \\
28 cycles & 158.18 & 183.26 \\
\hline
\end{tabular}



Figure 12. Fracture tests in AEAC samples before and after freeze-thaw cycles.

almost unnoticeable, with the results being similar in spite of the number of freeze-thaw cycles that they underwent.

The fracture energy of the AEAC and SFC concrete can be observed in table 5. The fracture energy of the SFC samples is almost constant across the experimental campaign. There is a slight reduction of the fracture energy in the samples subjected to four cycles, though this value grew subsequently. In the AEAC tests there was an increment of the fracture energy between cycles 0 and 14, with it being constant in the tests that ensued.

\section{DISCUSSION}

The results of the freeze-thaw tests showed that the resistance of the concrete manufactured with an air-entraining additive is superior to the resistance of SFC concrete. The three measuring systems used (mass loss, strain monitoring and measurement of the dynamic elastic modulus) each obtained coherent results and showed that freeze-thaw cycles caused damage in the SFC samples from the first cycle and that the damage rate increased as the cycles continued. This evidence may be deduced by observing figures 7, 9 and 10. Therefore, the argument that establishes that concretes manufactured with silica fume are resistant to freeze-thaw cycles should be questioned in those concretes with silica fume and low cement content. This was previously addressed in the research of Al-Assadi and Romero $(10,11)$ who explained that the different behaviour was a consequence of the changes in the microstructure. It is worthwhile pointing out that the strains measured in the SFC might have a great influence on the behaviour of a reinforced concrete structure. 


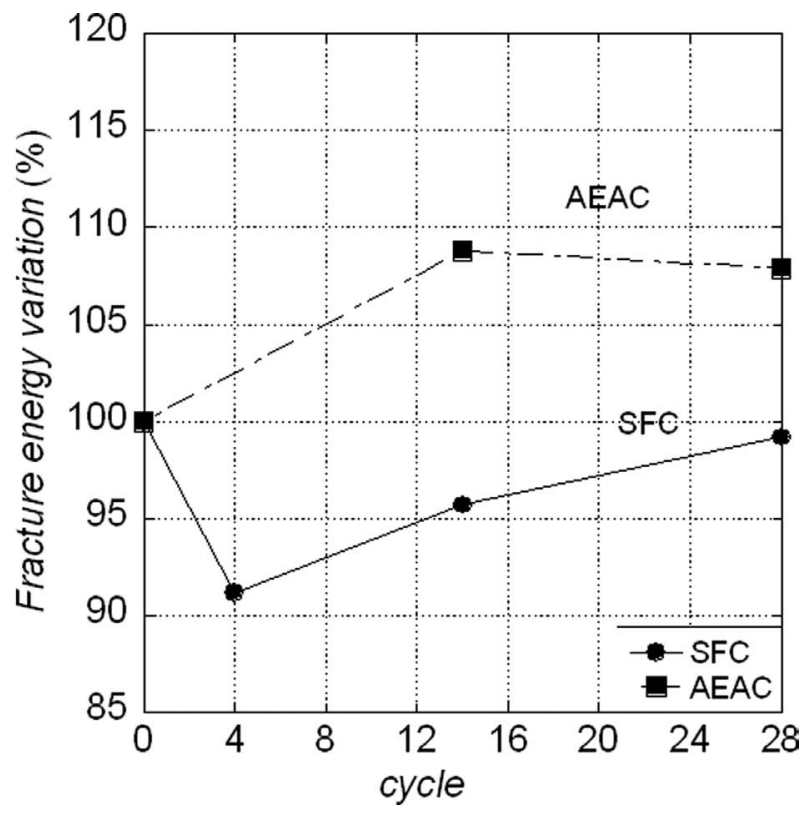

FiguRE 13. Percentage variation of fracture energy in SFC and AEAC.

A strain of one per one thousand would create an additional stress of $200 \mathrm{MPa}$ in steel reinforcement bars or might cause a redesign of an expansion joint of a road or a prestressed bridge bearing.

The fracture test results in figure 11 and 12 show that the maximum load is greater in the tests performed in AEAC samples. This is an unexpected phenomenon, not only because concrete manufactured with silica fume usually has better mechanical properties than normal concrete but also because it is widely known that air-entraining additives cause a reduction in strength (27). However, these results are coherent with the compressive strength results that can be seen in table 3 . The combination of a low compressive strength and a low maximum load in the fracture tests, it could be argued, denotes that the cement content is too low to generate enough porlandite to react with the silica fume and generate secondary silicates which are responsible for the strength increment.

The fracture energy obtained in the tests of the silica fume concrete is also lower than the AEAC. The values in table 5 show that the fracture energy of the undamaged AEAC concrete is $10 \mathrm{~N} / \mathrm{m}$ higher than the undamaged SFC fracture energy.

The evolution of the fracture energy with the freeze-thaw cycles may be observed in figure 13, where the undamaged fracture energy of both concretes has been considered as the reference $(100 \%)$. Therefore, an increment of the fracture energy will appear to be above $100 \%$ and the reduction of the fracture energy below this value. AEAC fracture energy increased by $7 \%$ during the freeze-thaw cycles. Conversely, SFC fracture energy decreased $10 \%$ in the first four cycles, rising subsequently up to values similar to those of the undamaged concrete.

The data in Table 5 and Figure 13 were obtained by dividing the area under the load-LVDT plots obtained in the fracture tests and the geometrical fracture area. The reduction and subsequent rise of the fracture energy of SFC shown in Figure 13 is not coherent with the results of the freeze-thaw tests shown in Figures 7, 9 and 10. In these figures, the damage of SFC increased monotonically which, therefore, led to a reduction of the mechanical properties being expected too.

Due to this discrepancy in the results, a detailed study of the fracture surfaces was carried out. Figure 14 shows the fracture surfaces of the SFC samples before and after the freeze-thaw cycles. The sample on the right side was not subjected to any cycle, whereas the sample on the left side was subjected to 28 freeze-thaw cycles. While in the lower third of both sections the notch is located, the rest of the area corresponds to the area generated during the

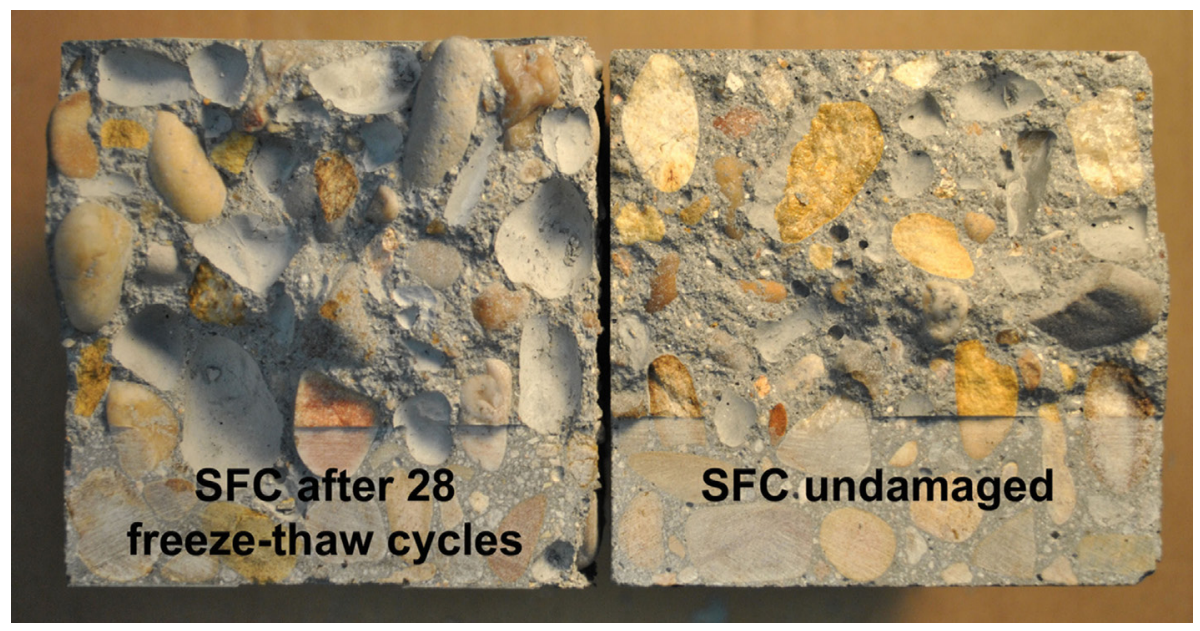

FIGURE 14. Fracture surfaces comparison between SFC samples before freeze-thaw cycles and after 28 freeze-thaw cycles. 


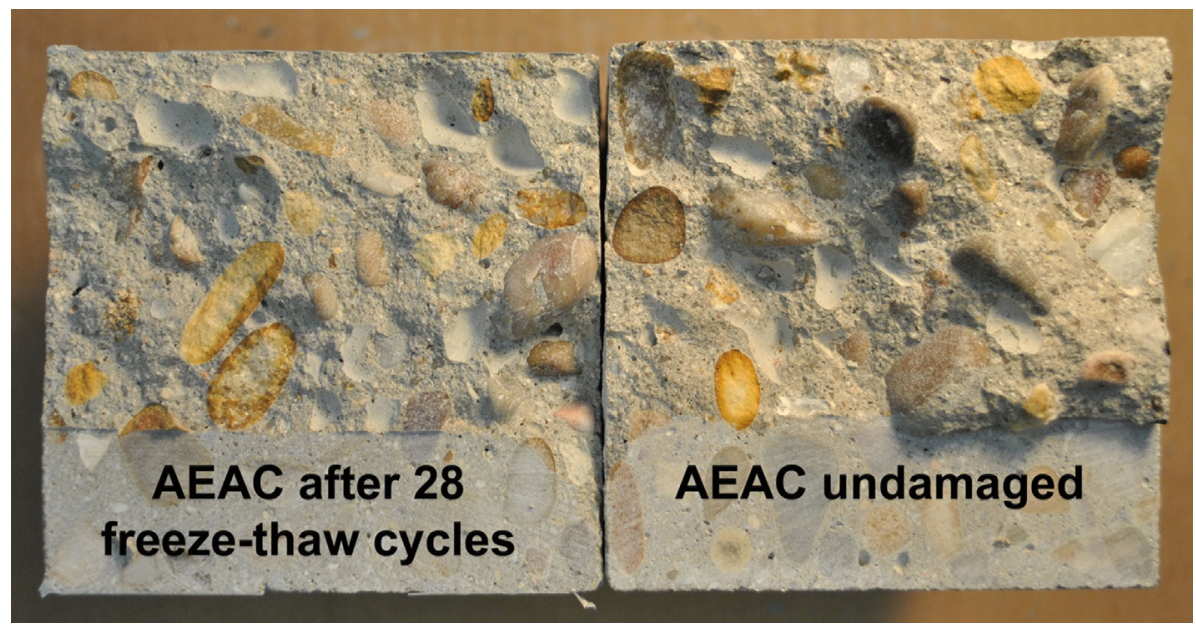

FIGURE 15. Fracture surfaces comparison between SFC samples before freeze-thaw cycles and after 28 freeze-thaw cycles.

fracture tests. The fracture surface of the undamaged samples may be described as almost flat and in it almost all the aggregates are fractured. In the case of the sample subjected to the freeze-thaw cycles, the fracture surface is noticeably irregular. There are hardly any aggregates fractured, with the majority being extracted or surrounded by the cracks. This leads to the scenario that while the projection of the fracture surfaces are identical, the real surface is notably greater in the samples subjected to 28 freezethaw cycles.

Regarding the AEAC samples that appear in figure 15 , there are hardly any differences between the samples before and after the freeze-thaw cycles. The sample not subjected to the cycles may be seen in the right part of the figure. This shows that there are some aggregates that have been fractured in the test and the remainder surrounded by the cracks.

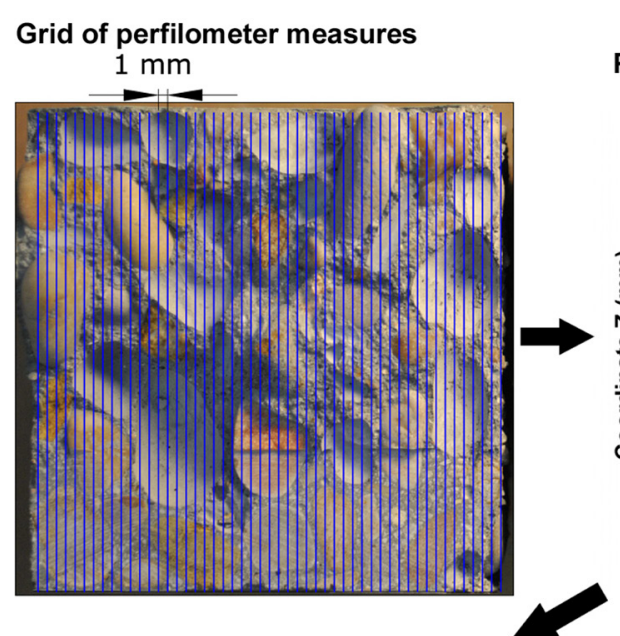

\section{Profile obtained in each measure}

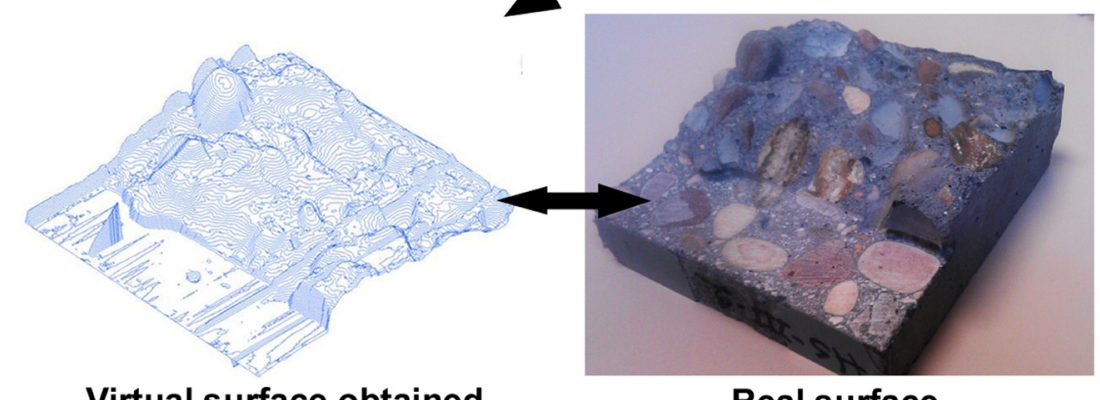

Virtual surface obtained

Real surface

FIGURE 16. Grid of measurements taken (top left), profile obtained (top right), virtual representation of the fracture surface (bottom left) versus real fracture surface (bottom right). 
TABLE 6. Fracture surface variation after freeze-thaw cycles. Plane surface is considered $100 \%$

\begin{tabular}{lcc}
\hline & \multicolumn{2}{c}{ Fracture area variation } \\
\cline { 2 - 3 } & SFC & AEAC \\
\hline 0 cycles & $128.7 \%$ & $126.7 \%$ \\
14 cycles & $138.2 \%$ & $125.5 \%$ \\
28 cycles & $143.1 \%$ & $127.1 \%$ \\
\hline
\end{tabular}

The same characteristics may be observed in the sample subjected to 28 freeze-thaw cycles.

The fracture areas generated in the tests have a significant influence on the values of the fracture energy of the material. The hypothesis assumed in the recommendation used in this study, (22) and that which has been previously used in other research papers (28), is that as the fracture surface is mainly flat and the area is thus equal to the geometric area of the section subtracting the notch. If this assumption is considered valid in the AEAC samples before and after the cycles and in the undamaged SFC samples, the jagged fracture surface of the SFC samples after the cycles overrides the hypothesis, as has been shown in figure 14. In this figure, it is clear that the fracture surface is larger than the theoretical because the cracks have grown through using the interface aggregate-cement paste that is the weakest part of the concrete. Therefore, the cracks generated in the damaged SFC samples have surrounded the aggregates, in contrast to the AEAC samples and the undamaged SFC samples where the aggregates were fractured. Although the energy consumed in the tests is similar, the fracture surfaces generated are greater in the damaged SFC samples.

In order to neglect the influence of the fracture surfaces created when obtaining the fracture energy, measurement of the areas of the formeris compulsory. The areas of the fracture surfaces were obtained by using a laser profilometer, with measurements being taken every $1 \mathrm{~mm}$ from one side of the sample to the opposite side. Only measurements for the samples where a direct comparison between the two types of concretes were carried out (cycle 0, 14 and 28).

The data acquired were used to generate $3 \mathrm{D}$ virtual models of the fracture surface and, through use of a surface analysis numerical code, the real fracture surfaces area have been obtained. Figure 16

TABLE 7. Fracture energy considering the fracture area variations produced by the freeze-thaw cycles

\begin{tabular}{lcc}
\hline & \multicolumn{2}{c}{ Concrete fracture energy (N/m) } \\
\cline { 2 - 3 } & SFC & AEAC \\
\hline 0 cycles & 123.86 & 134.14 \\
14 cycles & 110.46 & 149.69 \\
28 cycles & 110.51 & 144.12 \\
\hline
\end{tabular}

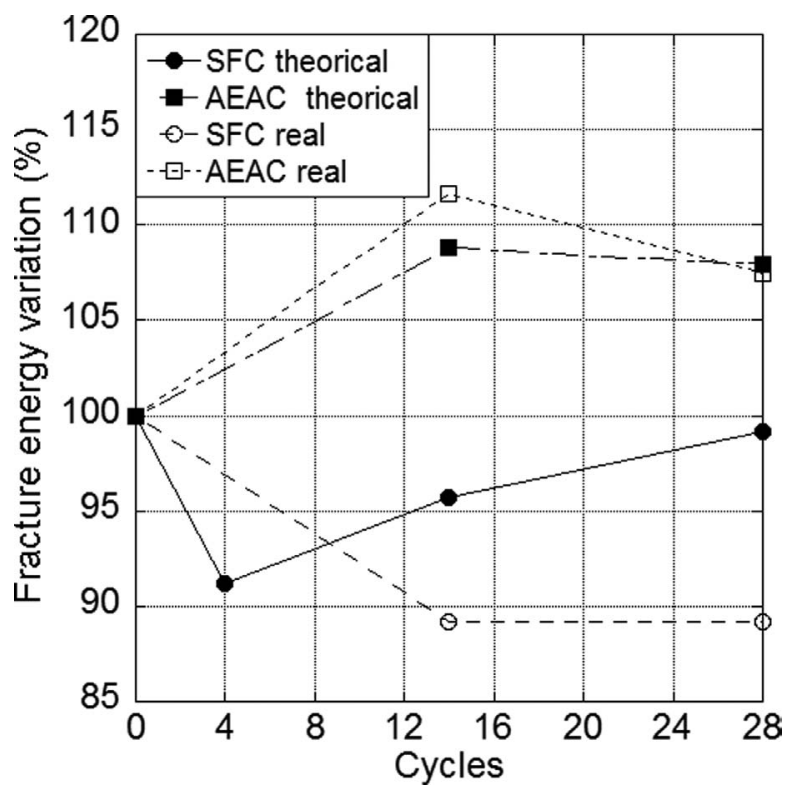

FigURE 17. Relative variation of the fracture energy in AEAC and SFC.

shows a sketch of the process employed to perform the virtual model of the surface and a comparison with the real surface.

Once all the areas were processed, it was clear that there were significant differences between the theoretical area and those produced in the tests. The measurements of the areas obtained for SFC and AEAC are shown in table 6 where $100 \%$ is considered the theoretical fracture area. In AEAC, samples the areas obtained were almost constant in all measurements and near to $26 \%$ greater than the theoretical. However, it is noticeable that the fracture areas of SFC samples grew as the number of cycles increased.

The data in Table 6, which refers to SFC samples, indicates that as the concrete is subjected to more cycles both the damage to the concrete and the fracture surfaces become greater. After 28 cycles the fracture surfaces generated are 15\% larger than those of the same undamaged material. This increment in the fracture surface might have been caused by the cracking of the concrete in the interface aggregate-cement paste.

If the changes in the areas are taken into account, the values shown in table 5 would be incorrect because they were obtained by dividing the energy consumption and the theoretical area, instead of by dividing the energy and the real area obtained through use of a profilemeter. In table 7 the values of the fracture energy are shown and take into account this modification.

In Figure 17 the relative change of the fracture energy can be compared by considering both the geometrical and the real fracture surface area. 
The fracture energy of SFC is reduced during the first 14 cycles, with it being constant between cycles 14 and 28. Figure 17 shows that the increment of the fracture energy of SFC is incorrect if the geometrical area of fracture is taken into account, because the real fracture surfaces are not similar before and after the cycles. If the real fracture surface area is employed in obtaining the fracture energy of SFC, the values decrease obtained are in concordance with the data obtained in the freeze-thaw tests.

In addition, the gradual unloading in the fracture tests of the samples subjected to the freeze-thaw test shown in figure 11 may also be explained by the differences in the fracture area generated. Given that the areas generated are greater, the unloading should be less steep than those observed in the samples with a limited damage.

The differences caused by using the real fracture area in the AEAC samples are less noticeable due to the slight differences between the theoretical and the real fracture surface area. The increment of the fracture energy of AEAC samples, it could be argued, may have been caused by the hydration process of the cement components during the first freeze-thaw cycles.

\section{CONCLUSIONS}

The main conclusions that may be derived from the tests carried out are the following:

As is well known, concrete with air-entraining additive (AEAC) possesses a good resistance to the freeze-thaw cycle test. However, the tests show that concrete without any additive but with silica fume (SFC), which is usually adopted as an alternative to face freeze-thaw cycles when prestressed reinforcement is employed, might perform worse. To obtain a concrete with silica fume resistant to freeze-thaw cycles, it is necessary to use reduced water/cement ratios and high-cement contents.

The fracture energy obtained in AEAC samples in not reduced by the freeze-thaw cycles, which indicates that the material is undamaged. The fracture surfaces of the samples manufactured with this concrete before and after the cycles are mainly flat and similar. This enables use of the recommendation of obtaining the fracture energy (22).

At cycle 14 the fracture energy of SFC concrete decreases by approximately $10 \%$, with it remaining constant until cycle 28 . This indicates that the main damage takes place during the initial cycles of the test. The use of the recommendation to obtain the fracture energy might lead to inaccurate results, due to an increment of the fracture surface area as the cycles increase $(22,23)$. Such an increment occurs because the damage in the concrete is focused on the interface aggregate-cement paste. It is at this interface where the cracks are concentrated during the fracture tests and irregular fracture surfaces are obtained. In such a situation, use of the real fracture surface instead of the theoretical fracture surface enables identification of the correct values of the fracture energy.

Measurement of the fracture energy of the concrete is an add-on to the other systems of ascertaining the freeze-thaw damage, such as measuring the surface mass loss (17), the strain of the samples and / or the ultrasonic pulse attenuation in the internal damage tests (29). The results obtained confirm that all the results obtained through the fracture energy and by measuring the surface mass loss are coherent with other testing procedures. Regarding the internal damage, even more evident results - due to the internal cracking that might take place - are to be expected.

The use of the specific fracture energy as a characterisation parameter of the concrete in the Model Code (30) might be revised and adapted when applied to damaged concrete. Some aspects, such as the increment of the fracture surface area with the freeze-thaw cycles, which is uncommon in undamaged concrete, might lead to imprecise values of the fracture energy.

\section{ACKNOWLEDGMENTS}

The authors wish to express their gratitude to the Ministerio de Economía and Competitividad for the grants DPI2011-24876 and IPT-42000-2010-31.

\section{REFERENCES}

1. Ministerio de Fomento. Code on Structural Concrete EHE08. (2008). (English version available at www.mfom.es).

2. Jacobsen, S.; Sather, D.H.; Sellevold, E.J. (1997) Frost testing of high strength concrete: frost/salt scaling at different cooling rate. Mat. Struct. 30 [1], 33-42. http://dx.doi. org/10.1007/BF02498738

3. Valenza, J.J.; Scherer, G.W. (2007) A review of salt scaling: I. Phenomenology. Cem. Concr. Res. 37 [7], 1007-21. http:// dx.doi.org/10.1016/j.cemconres.2007.03.005.

4. Valenza, J.J.; Scherer, G.W. (2007) A review of salt scaling: II. Mechanisms. Cem. Concr. Res. 37 [7], 1022-34. http:// dx.doi.org/10.1016/j.cemconres.2007.03.003.

5. Mays, G.; Wang, K. (2009) Effects of Strength, Permeability, and Air void Parameters on Freeze-thawing Resistance of Concrete with and without Air Entrainment. Journal of ASTM International. 6 [10]. doi: 10.1520/JAI102454

6. Sabir, B.B.; Kouyiali, K. (1991) Freeze-thaw durability of air-entrained CSF concrete. Cem. Concr. Compos. 13 [3], 203-208. http://dx.doi.org/10.1016/0958-9465(91)90021-9.

7. Sabir B.B. (1997) Mechanical properties and frost resistance of silica fume concrete. Cem. Concr. Compos. 19 [4], 285-294. http://dx.doi.org/10.1016/S0958-9465(97)00020-6.

8. Halit, Y. (2008) The effect of silica fume and high-volume Class C fly ash on mechanical properties, chloride penetration and freeze-thaw resistance of self-compacting concrete. Constr. Build. Mater. 22 [4], 456-462. http://dx.doi. org/10.1016/j.conbuildmat.2007.01.002

9. Bleszynsky, R.; Hooton, R.D.; Thomas, D.A.; Rogers, C.A. (2002) Durability of ternary blend concrete with silica fume and blast furnace slag: Laboratory and outdoor exposure site studies. ACI Mater. J. 99 [5], 499-508.

10. Al-Assadi, G. (2009) Influencia de las condiciones de curado en el comportamiento del hormigón sometido a 
ciclos hielo-deshielo, Ph.D Thesis, Universidad Politécnica Madrid.

11. Al-Assadi, G.; Casati, M.J.; Fernandez, J.; Gálvez, J.C. (2011) Effect of the curing conditions of concrete on the behaviour under freeze-thaw cycles. Fatigue Fract. Eng. Mater. Struct. 34 [7], 461-469. http://dx.doi.org/ $10.1111 / \mathrm{j} .1460-2695.2010 .01520 . \mathrm{x}$

12. Romero, H.L. (2011) Deterioro del hormigón sometido a ensayos acelerados de hielo-deshielo en presencia de cloruros. Ph.D Thesis, Universidad Politécnica Madrid.

13. Shang, H.S.; Song, Y.P. (2006) Experimental study of strength and deformation of plain concrete under biaxial compression after freezing and thawing cycles. Cem. Concr. Res. 36 [10], 1857-1864. http://dx.doi.org/10.1016/j. cemconres.2006.05.018

14. Shang, H.S.; Song, Y.P.; Qin, L.K. (2008) Experimental study on strength and deformation of plain concrete under triaxial compression after freeze-thaw cycles, Build. Environ. 43 [7], 1197-1204. http://dx.doi.org/10.1016/j. buildenv.2006.08.027

15. Shang, H.S.; Song, Y.P.; Ou, J. (2009) Behavior of airentrained concrete after freeze-thaw cycles, Acta Mech. Solida Sin. 22 [3], 261-266. http://dx.doi.org/10.1016/ S0894-9166(09)60273-1

16. Shang, H.S.; Song, Y.P. (2013) Triaxial compressive strength of air-entrained concrete after freeze-thaw cycles, Cold Reg. Sci. Technol. 90-91, 33-37. http://dx.doi.org/10.1016/j. coldregions.2013.02.002.

17. AENOR. UNE-CEN/TS 12390-09, (2009) Testing hardened concrete. Part 9: Freeze-thaw resistance. Scaling.

18. ASTM. C231/C231M-10 (2010) Standard Test Method for air content of freshly mixed concrete by the pressure method.

19. Bishnoi, S., Uomoto, T. (2008) Strain-temperature hysteresis in concrete under cyclic freeze-thaw conditions. Cem. Concr. Compos. 30 [5], 374-380. http://dx.doi.org/10.1016/j. cemconcomp.2008.01.005
20. Enfedaque, A.; Al-Assadi, G.; Romero, H.L.; Gálvez, J.C.; Zhe,W. (2011) Durabilidad del hormigón frente a los ciclos hielo-deshielo. Evaluación de dos tipos de hormigón. Anales de la Mecánica de la fractura XVIII. 675-680.

21. Romero, H.L.; Casati, M.J.; Gálvez, J.C.; Molero, M.; Hernández, M.G.: (2011) Deterioro del hormigón sometido a ciclos de hielo-deshielo en presencia de cloruros. Anales de la Mecánica de la fractura XVIII. 669-674.

22. Planas, J.; Guinea, G.V; Gálvez, J.C.; Sanz, B.; Fathy, (2007) Indirect tests for stress-crack opening curve. A.M. RILEM TC-187-SOC.

23. RILEM TC 50-FMC. (1985) Determination of the Fracture Energy of Mortar and Concrete by means of Three-point Bend Test on Notched Beams. Mater. Struct. 18, 285-290. http://dx.doi.org/10.1007/BF02472918

24. Du, L.; Folliard, K.J. (2005) Mechanisms of air entrainment in concrete, Cem. Concr. Res. 35 [8], 1463-1471. http:// dx.doi.org/10.1016/j.cemconres.2004.07.026

25. Penttala, V.; Al-Neshawy, F. (2002) Stress and strain state of concrete during freezing and thawing cycles. Cem. Concr. Res., 32 [9], 1407-1420. http://dx.doi.org/10.1016/j. cemconres.2004.07.026

26. Setzer, M.J. (2001) Micro-Ice-Lens Formation in Porous Solid. J.Colloid Interface Sci. 243 [1], 193-201. http:// dx.doi.org/10.1006/jcis.2001.7828

27. Fernández Cánovas, M. (2010) Hormigón. Colegio de Ingenieros de Caminos, Canales y Puertos.

28. Fathy A.M.; Sanz B.; Sancho J.M.; Planas J. (2008) Determination of the bilinear stress-crack opening curve for normal- and high-strength concrete, Fatigue Fract. Eng. Mater. Struct. 31 [7], 539-48. http://dx.doi. org/10.1111/j.1460-2695.2008.01239.x

29. ASTM. C666/C666M-03 Standard Test Method for resistance of concrete to rapid freezing and thawing. 2008.

30. Model Code 2010, Final Draft, FIB Bulletin 65 \& 66, Lausanne, Swizterland, 2012. 